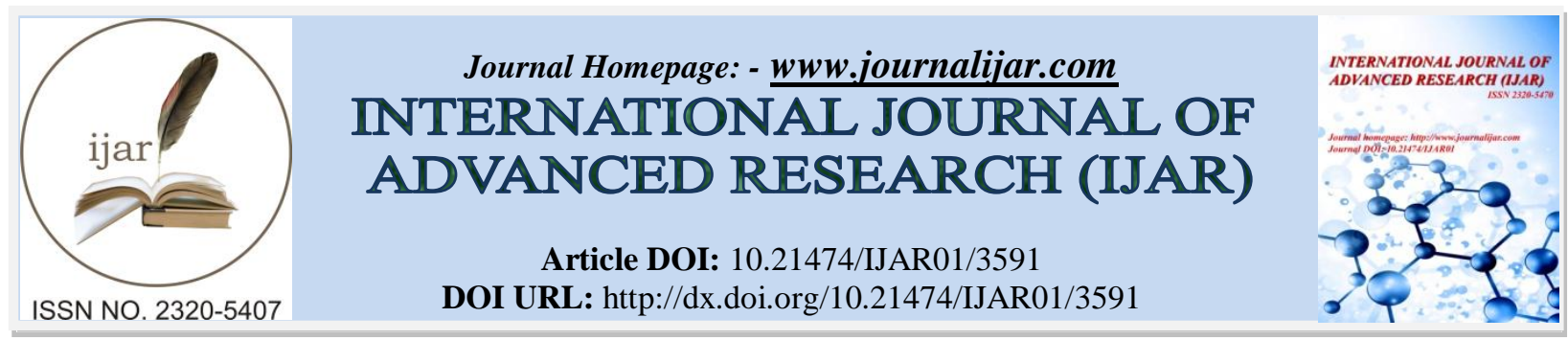

RESEARCH ARTICLE

\title{
DRAFTING AND REVISING STRATEGIES TO DEVELOP ENGLISH ESSAY BY INDONESIAN EFL LEARNERS.
}

Imroatus Solikhah, Jl. Pandawa and Pucangan Kartasura.

State Islamic Institute of Surakarta, Indonesia.

\section{Manuscript Info}

Manuscript History

Received: 05 January 2017

Final Accepted: 03 February 2017

Published: March 2017

Key words:-

drafting, revising, writing process, proofreading.

\begin{abstract}
This qualitative study reports features of drafting, revising and strategies to write an English essay. The study was done in State Islamic Instute (IAIN) Surakarta, Indonesia on January to April 2015, assigning 30 students as the research subject. The study revealed that in drafting and revising process in writing were differently produced by lower, middle and upper groups. Lower group did not write outline and produced first draft without planning. Thesis statement, topic sentence and concluding paragraph did not appear. The middle gruop was able to produce thesis stetament, body paragraphs and conclusion, but they focused less on revising and proofreading. The upper group exhibitted by performing all aspects of an essay in each rhetorical patterns. Drafting and revising were used appropriately. All groups asserted literal translation to develop ideas and overcome problems on diction.
\end{abstract}

Copy Right, IJAR, 2017,. All rights reserved.

\section{Introduction:-}

Good writing is essential for success in school and the 21 st Century workplace. Writing is a complex combination of skills which is best taught by breaking down the process. The writing process involves a series of steps to follow in producing a finished piece of writing. Focusing on the process of writing, almost everyone learns to write successfully. By breaking down writing step-by-step, the mystery is removed and writer's block is reduced. Most importantly, students discover the benefits of constructive feedback on their writing, and progressively master, and even enjoy, writing (Time4 Writing, 2016).

The writing process - prewriting, drafting, revising and editing, rewriting, publishing-mirrors the way proficient writers write. Studies show that students who learn the writing process score better on writing tests than those who receive only specific instruction in the skills assessed on the test. Success in writing greatly depends on a student's attitude, motivation, and engagement. The writing process takes these elements into account by allowing students to plan their writing and create a publishable, final draft of their work of which they can be proud (ILA/NCTA, 2017:1).

When teaching expository essay in Indonesian contexts, empirical evidences appear pertaining to quality of rethorical patterns. There is still a debate if process of writing is empasized, attentions in the language revision will decline and improvements on grammar are limited. Conversely, if language corrections take priority, writing process is delayed.

For many students, writing can be intimidating, upsetting and mystifying but writing process answers this problem. Every writer follows his or her own writing process (Pouladian, et. al. 2017). Therefore, process writing has been 
considered as writing technique that suffices benefits in the teaching process. According to Krashen (1984:21) convention as a model is required in process of writing. To maintain how to write for newspaper, read newspapers; textbooks about them will not suffice. For magazines, browse through magazines rather than through correspondence courses on magazine writing. To write poetry, read it. For the conventional style of memoranda in a school, consult school file.

\section{Research Questions:-}

1) How is the feature of revising and drafting the English essay by Indonesian EFL learners?

2) How are elements of introductory paragraph, body paragraphs and concluding paragraph in an essay by Indonesian EFL learners?

3) What strategies are used by Indonesian EFL learners to develop an essay?

\section{Review of Litarature:- \\ Process Writing:-}

Historically, educators have struggled how to write well, focusing on the finished product. Since the 1970s, teachers no longer emphasize the finished product; instead, they teach the writing process. Researchers discovered that writing was a highly complex process, made up of various sub-processes that had a strict linear sequence and varying patterns (Caudery, 1995). Good writers differ from poor writers in their composing process, that is, they have better and more sound procedures for getting their ideas down on paper. Specifically, good writers differ in three ways: in planning, rescanning, and revising (Krashen, 1984:12).

Writing is recursive and any of the steps can be repeated. The term recursive refers that writers can engage in any act of composing--finding ideas, thinking about ways of organizing them, imagining ways of expressing them--at any time during writing and often perform these acts many times while writing (Wingersky, Noerner, \& HolguinBalogh, 1992; Langan, 1992). In addition, Krashen (1984:17) asserts writers employ recursive: writing a draft may be interrupted by more planning, and revision may lead to reformation, with a great deal of recycling to earlier stages. According to Caudery (1995) students can start the process from brainstorming, prewriting outline or collection of ideas in their head. Students also create a topical outline to help organize their ideas, and to develop a working thesis statement.

Weaknesses and benefits of writing process exist, however. Because the emphasis is on the process of writing, much of the sensitivity about receiving constructive criticism is eliminated. The strength is its usefulness for a wide range of diverse learners. Students are taught a variety of styles to structure their thinking, ranging from analytical outlines to highly visual graphic organizers. Students explore ways for organizing and visualizing their ideas that is the most effective for them.

\section{Steps of Process Writing:-}

Simply, process writing consists of five steps to write a piece of writing product. Often the process is a routine that comes naturally and is not a step-by-step guide to writer. Here are five steps of the writing process.

\section{Pre-writing:-}

Prewriting is a planning phase in writing process. Here students brainstorm, research, gather and outline ideas in terms of diagrams for mapping out their thoughts. Students also address audience and purpose, and formulate a thesis statement for the writing. Prewriting includes: (1) Deciding on a purpose, or reason, for writing. (2) Thinking about the audience's needs and interests. (3) Choosing a subject for writing. (4) Limiting the subject to a suitable topic. (5) Gathering information on the topic. (6) Organizing the information (Langan, 1996).

\section{Drafting:-}

The second process of writing is composing a first draft or rough draft. A draft is the rough form of a piece of writing. Definitely, drafting is writing the first version of ideas on a paper without thinking right or wrong the ideas are. Writing the first draft is expressing ideas in sentences and paragraphs. Drafting involves taking information the writer has generated and organized in an essay. The writer consciously starts with main ideas and adds supporting ideas that flow smoothly (Wingersky, Noerner, \& Holguin-Balogh, 1992). Students create initial composition by writing down all their ideas in an organized way to convey a particular idea or present an argument. Audience and purpose are finalized later. 


\section{Revising:-}

Revising means to see again. Revising is a big change like wording, adding sentences, and moving paragraphs. In writing, revising is making changes to improve the first draft by moving around words, phrases, and ideas. Writers review, modify, and reorganize their work by rearranging, adding, or deleting content, and by making the tone, style, and content appropriate for the intended audience (Warriner, 1988; Langan, 1998; Nordquist, 2015). When revising, a writer is changing the meaning or way in which the reader perceives, experiences and interprets it.

Prior to revising, a writer does an evaluation on the paper, that is, re-examining ideas, organization, and word choice in the first draft (Langan, 1996). A space for improvement appears in the first draft and to improve this, the writer evaluates or makes judgements on strengths and weakness of the draft to see intended purpose of the paper, organization, clarity, and appropriateness to its audience (ILA-NCTE, 2017). See Table 1 for the guideline of evaluating a paper.

In addition, revision focuses on the whole paper. It may change several points: point of view, tone of paper, order of paragraphs, eliminating one of the paragraphs completely, adding a whole new idea, and changing conclusion (Nordquist, 2015). Revising naturally adopts the ARRR approach:

Add: number of words or details required, e.g. 350 or 3,500 words

Rearrange: organization or contents of the paper appropriately

Remove: making changes, organization, rearrange ideas, eliminate passages

Replace: enough details, any contradicted facts

Table 1:- Guidelines for Evaluating Writing (Warriner, 1988:32-33)

\begin{tabular}{|l|l|l|}
\hline Contents & $\begin{array}{l}1 . \text { Do all the ideas help to achieve a main purpose (explain, tell a story, } \\
\text { describe, or persuade)? }\end{array}$ \\
\hline 1 & Purpose & 2. Is the topic suitably limited for the form of writing? \\
\hline 3 & Topic & 3. Are the topic and details suitable for the audience? \\
\hline 4 & Development & $\begin{array}{l}\text { 4. Is enough information given to understand the topic? Is too much } \\
\text { given - does it all "belong?" }\end{array}$ \\
\hline Organization & $\begin{array}{l}\text { 1. Does the order of ideas fit the purpose? Will this order make sense to } \\
\text { the reader? }\end{array}$ \\
\hline 1 & Coherence & $\begin{array}{l}\text { Are ideas clearly connected, with words such as also, first, these, } \\
\text { however, and therefore? }\end{array}$ \\
\hline 2 & Transition & 1. Are exact and vivid words used? \\
\hline Style & \multicolumn{2}{|l|}{ Does the vocabulary fit the audience and purpose? } \\
\hline & Words Choice & 3. Do the sentences vary in length and how they begin? \\
\hline
\end{tabular}

Table 2 is presented to show how revising activities and its focus should work in a small scope.

Table 2:- Revising focus on a paper (Adapted from Monica (1996), Student Learning Center, University of California, Berkeley).

\begin{tabular}{|l|l|}
\hline No & Focus of Revision \\
\hline 1 & $\begin{array}{l}\text { A paper as a whole: strengths, weaknesses, arguments, focus, organization, support, voice, and mechanical } \\
\text { issues }\end{array}$ \\
\hline 2 & $\begin{array}{l}\text { Dialogue-based, the purpose or revision is to ask questions, expanding ideas and challenging arguments } \\
\text { which require discussion between the writer and the reader }\end{array}$ \\
\hline 3 & $\begin{array}{l}\text { Non-hierarchical, offering questions and making observations, allow the writer and reader to hold separate } \\
\text { and valid opinions. The purpose is to expand and clarify ideas rather than correct them }\end{array}$ \\
\hline 4 & $\begin{array}{l}\text { focuses on the writer in the process of writing and increasing the writer's understanding of the paper's } \\
\text { strengths and weaknesses }\end{array}$ \\
\hline 5 & $\begin{array}{l}\text { Clarifies and focuses the writer's arguments by defining terms, making concessions and counter-arguments, } \\
\text { and using evidence; moving or removing entire paragraphs, extending or narrowing ideas, rewriting vague } \\
\text { or confusing text, and adding to existing paragraphs }\end{array}$ \\
\hline
\end{tabular}


More complete version of revising activities, Table 3 is presented as a guidance of revising for a paper in a broader context.

Table 3:- Revising a Draft (adopted from Warriner, 1988: 35-36)

\begin{tabular}{|c|c|c|c|}
\hline No & Problem & Techniques & Revision \\
\hline 1 & Purpose is not clear & Add/Cut & $\begin{array}{l}\text { Make sure you know your purpose. Add details that fit } \\
\text { it. Remove comments that do not fit it. }\end{array}$ \\
\hline 2 & The ideas are too general & Replace & $\begin{array}{l}\text { Make general ideas more specific. Do more research, if } \\
\text { needed. Be sure the topic is not too broad for the form } \\
\text { of writing. }\end{array}$ \\
\hline 3 & $\begin{array}{l}\text { Some information is } \\
\text { "extra" or not related to the } \\
\text { main idea. }\end{array}$ & Cut & $\begin{array}{l}\text { Remove "padding" and unrelated ideas. Keep only the } \\
\text { background needed by the particular audience. }\end{array}$ \\
\hline 4 & $\begin{array}{l}\text { It is hard to follow the } \\
\text { ideas. }\end{array}$ & Reorder/Add & $\begin{array}{l}\text { Move sentences or paragraphs to fit what a reader needs } \\
\text { to know first, second, and so on. Add linking words } \\
\text { such as this, when, then, these. }\end{array}$ \\
\hline 5 & $\begin{array}{l}\text { Some terms are too } \\
\text { complex or too simple for } \\
\text { the audience. }\end{array}$ & Add/Replace & $\begin{array}{l}\text { Add definitions to explained unfamiliar terms. Change } \\
\text { the wording to fit the audience's age and background. }\end{array}$ \\
\hline 6 & The beginning is dull & Add & $\begin{array}{l}\text { Add examples, incidents, or other details that will } \\
\text { interest the audiences. Be sure the topic will interest the } \\
\text { audience. }\end{array}$ \\
\hline 7 & $\begin{array}{l}\text { Some words are vague or } \\
\text { overused. }\end{array}$ & Replace & $\begin{array}{l}\text { Replace words that stand for a group of things with } \\
\text { more exact words. Use exact, vivid adjectives, adverbs, } \\
\text { and verbs. }\end{array}$ \\
\hline 8 & $\begin{array}{l}\text { Some wording seems very } \\
\text { informal. }\end{array}$ & Cut/Replace & $\begin{array}{l}\text { When light, informal expressions do not fit the purpose } \\
\text { and audience, remove slang, contractions, and so on or } \\
\text { replace them with standard formal words. }\end{array}$ \\
\hline 9 & $\begin{array}{l}\text { The sentences are } \\
\text { monotonous. }\end{array}$ & Replace/Reorder & $\begin{array}{l}\text { Combine choppy sentences. Split rambling sentences. } \\
\text { Change the word order so sentences begin in different } \\
\text { ways. }\end{array}$ \\
\hline
\end{tabular}

\section{Editing:-}

Editing begins as soon as a writer finished the first draft. Editing is rereading draft to see whether paper is wellorganized, transitions between paragraphs are smooth, and evidences really fit the argument (Langan, 1996). Editing takes place in two ways: First, editing focuses on errors on punctuation, grammar, and spelling. In this stage, editing a manuscript focuses only on the structure of writing that is to be corrected. These are minor changes that include: spelling, grammar, punctuation, sentence structure. The overall text remains exactly the same because an editor simply corrects mistakes in the paper, such as typos, grammar errors, and spelling mistakes (Time4 Writing, 2016). Second, editing undergoes with linkages of developments and connections of ideas in the whole paper. This way, level of editing includes: contents (claim, argument, evidence, relevant goal), overall structure (thesis statement, introduction, body, conclusion, logical sequence, transitions between paragraphs), and structure within paragraph (clarity, style, citation) (The Writing Center at University of North Caroline. 2014). Table 4, shows activities how an editing a paper should work.

Table 4:- Focus of Editing (Adapted from Monica (1996), Student Learning Center, University of California, Berkeley).

\begin{tabular}{|c|c|}
\hline No & Focus of Editing \\
\hline 1 & A sentence level, addressing problems with spelling, grammar, punctuation, or word choice \\
\hline 2 & One-sided: The editor writes comments and corrections on the paper and returns the paper to the writer \\
\hline 3 & $\begin{array}{l}\text { Hierarchical: An editor looks for "mistakes" and "fixes" them. An editor places value on writing (such as a } \\
\text { grade) }\end{array}$ \\
\hline 4 & Focuses on the paper as a product \\
\hline
\end{tabular}


After editing, the editor's job is proofreading. Errors in spelling, grammar, usage, or mechanics can distract the reader from the ideas in the paper. At this point, writers proofread and correct errors in grammar and mechanics, and improve style and clarity. It's time to fine tune the manuscript line by line by checking for repetition, clarity, grammar, spelling and punctuation. Proofreading consists of checking for errors in grammar, usage, mechanics, and correcting errors. The result of conscientious proofreading is a final draft-the finished product (Time4 Writing, 2015; Nordquist, 2015).

Proofreading is different from revision. Proofreading is the final stage of the editing process, focusing on surface errors such as misspellings and mistakes in grammar and punctuation. Proofreading is done only after all editing revisions are finished. Proofreading is finding and correcting mistakes in grammar, usage, and mechanics. Usage means using words correctly according to the rules for standard written English. Mechanics includes capitalization, punctuation, and spelling (Langan, 1996). See Table 5 for the guidelines of proofreading.

Table 5:- Guidelines for Proofreading (adopted from Warriner, 1988: 39)

\begin{tabular}{|l|l|}
\hline No & Focus to proofread \\
\hline 1 & Do plural verbs have plural subjects? Do singular verbs have singular subjects? \\
\hline 2 & Are verbs in the right form and tense? \\
\hline 3 & Are the verbs sit/set, rise/raise, and lie/lay used correctly? \\
\hline 4 & Are subject and object forms of pronouns used correctly? \\
\hline 5 & Are adjective and adverb forms used correctly in comparison? \\
\hline 6 & Are double negatives avoided? \\
\hline 7 & Do all sentences and proper nouns and adjectives begin with a capital letter? \\
\hline 8 & Are all words spelled correctly? Have spellings been checked in a dictionary? \\
\hline 9 & Is the punctuation correct at the ends of sentences and within sentences? \\
\hline 10 & Is every sentence a complete sentence? \\
\hline
\end{tabular}

\section{Publishing:-}

Publishing is the last step of the writing process. Publishing is making the final copy of the paper into a correct form. Publishing for English teachers and students means the completion of the cyclical writing process for a specific product. The writer prepares a document to be distributed to an audience. This may involve printing the work or duplicating it in print or online.

\section{Writing Process in This Study:-}

Overall writing process is presented in Figure 1. Parts of this process cannot operate at the same time, even if the writer is skilled and the writing task is easy. Altogether they represent what is called the writing process that is recursive, which means going back and forth. Writing process in this study includes three steps and two activities of writing: drafting and revising.

\section{Drafting}

a. Stage One : Exploring-Experimenting-Gathering information

b. Stage Two : Writing the controlling idea/Organizing and developing support

Revising

c. Stage Three : Writing-Revising-Editing. 


\section{Diagram of Process Writing}

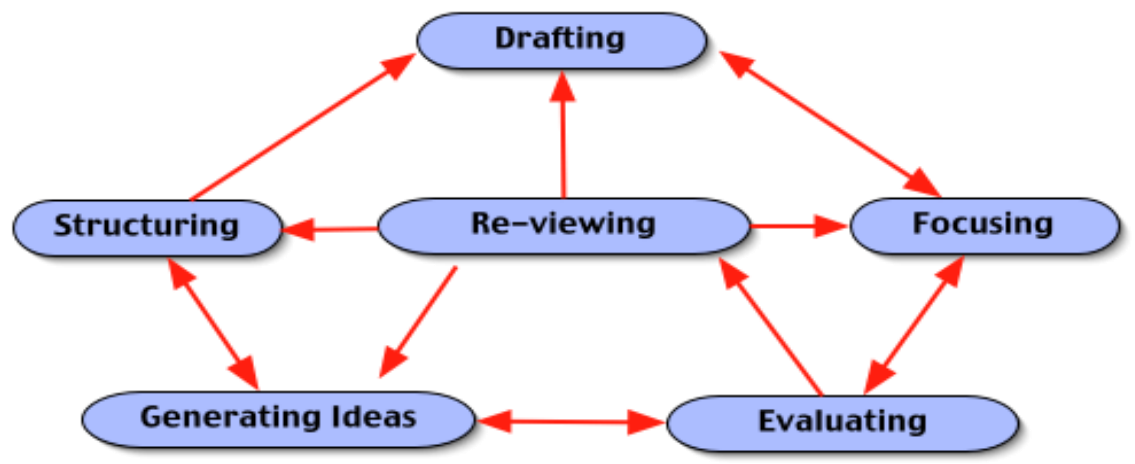

Figure 1:- The Process of Writing (from: Process Writing by Ron White and Valerie Arndt, 1991.)

\section{English Essay:-}

An essay is a piece of writing several paragraphs long. An essay is usually divided into several paragraphs, tying together an introduction, body and a conclusion (Oshima and Hogue, 2006). An essay is a short piece of nonfiction writing that often requires a number of skills such as close reading, analysis, comparison and contrast, persuasion, conciseness, clarity, and exposition (Langan, 2009). The purpose is to develop ideas and concepts more formal, concise, clarity in purpose and direction.

Standard short essay is between 350 and 500 words long; usually has one paragraph of introduction, a threeparagraph body, and one paragraph of conclusion. Some essays have two to three paragraphs, others have twenty or thirty. The essays written in class contain from four to six paragraphs, with the most common number being five: one introductory paragraph, three developmental paragraphs, and one concluding paragraph (Smalley and Ruetten, 1982:139). A-500 essay is equal to one page A4 paper for single space. A long essay such as paper or journal article may consist of 3,500 to 6,000 words long or 8-10 pages typed in a single space format. Organization of the paper normally includes: title, author name, abstract, introduction, review of literature, methodology, findings, discussion, conclusion and reference (Solikhah, 2017).

The introduction, the first section of an essay, is usually one paragraph that introduces topic to be discussed and central idea (the thesis statement) of the essay. The purpose is to arouse interest and introduce the controlling idea of an essay and states the main idea and thesis statement. The thesis statement is called the controlling idea that brings an essay into focus, giving it direction and drawing its ideas together (Kirszner and Mandell, 1978:5).

The body paragraphs are the longest section of an essay. In a short essay, there are usually three body paragraphs, each one considering in detail one aspect of the essay's controlling idea. This is called a three-point essay. These paragraphs develop various aspects of the topic and the central idea. They may discuss causes, effects, reasons, examples, process, classification, or points of comparison and contrast. They may also describe or narrate (Smalley and Ruetten, 1982:139).

The concluding paragraph is the end of an essay that concludes the thought developed in the essay as the closing word. The ideas in the conclusion must be consistent with the rest of the essay. In the conclusion, the writer should draw together all that has come before by restating the controlling idea of the essay. This statement is usually most effective when it is located at the beginning of the conclusion (Kirszner and Mandell, 1978:7).

\section{Methodology:- \\ Research Design:-}

This study used descrptive design with qualitattive approach aiming to explain writing process on the accomplishment of expository essay. Writing process in this study was restricted into two kinds: drafting and revising. Descriptivey, the study deliniated drafting and revising in terms of frequency and rate percentage; in ddition, elaboration of the rate percentage was done through explanation on the statements of writing comments. This study took place in English department at State Islamic Institute (IAIN) at Surakarta, Indonesia and conducted from January to April 2015. 


\section{Research Subject:-}

Subjects of this study were senior 30 students learning in the sixth semester of English Language Education program of IAIN Surakarta joining in Writing Class. As this research ended, there were 5 students absent so the final number of participants were 25 students, 17 female and 8 male. Subjects were all at about to have similar competence in writing as all have received courses on Paragraph Writing, Essay Writing and Academic Writing at respective previous semester prior to this research was conducted. To this end, their knowledge on writing convention, academic writing, process of writing, and strategies of writing was equal among students. Subjects were all aware that they were incurred in the research class of writing the reseracher conducted and they received treatments on the same materials.

\section{Research Instruments:-}

Instruments of this study were Writing Prompt on Expository Essay, Checklist to Assess Expository Writing, and Interview Guide. Writing promot was used to see writing students worked. The expository test asked students to write an English essay of 5-10 pargarph with 350 to 750 words length. The mode of the essay was expository that explained a topic the researcher determined in the writing prompt. The essay checklist was used to evaluate the availability of the components of the essay After each essay was evaluated by raters and scores had been provided in each essay, the researcher classified the essay into three categories: low, middle and high. Based on the quality, the researcher interviewed to the subjects to see the strategies, process, and the works during preparations on drafting and revising process in developing the essay.

\section{Data and Sources of Data:-}

Sources of data in this study was Expository Essay obtained from the test of writing done by the research subjects. The essays were assessed and scored its quality. Therefore, data of the study comprised of quality of the intriductory paragraph, the body paragraphs, and the concluding paragraph. Data on elements to support good introductory paragraph (e.g. thesis statement), the body (e.g. transition words, details, coherence) and the concluding paragraph (e.g. restatement of topic) were also identified.

\section{Data Analysis Techniques:-}

Data of this study consisted of two main concerns: frequency account and narrative accounts. First of all, the essays were scored and were identified their rhetorical patterns. The presennce of account on each rhetorical patterns and its components were identified. Frequency data were used for two main concerns of analysis; First, it indicated frequency used by low, middle, and upper students during drafting and revising process to include in the rhetorical patterns; Second, it showed an account of how each group of the subject used elements of rhetorical patterns to build good introductory paragraph, the body and concluding paragraph.

In addition, exploration on comments and opinions of the subjects obtained through interview was used to collect narrative data. The interview described subjects' testimony on how they worked during the process of writing. Data of this view were categorized into strategies, problems, challenge and attitude during the writing expository essay in this study.

\section{Results:-}

\section{Drafting and Revising the Essay:-}

Table 5 summarizes frequency of account on drafting and revising to develop an essay. Analysis was focused on frequency of correct form in drafting and revising to develop rhetorical patterns of an essay.

Table 5:- Drafting \& Revising to Develop Rhetorical Patterns

\begin{tabular}{|l|l|l|l|l|l|l|l|l|}
\hline No & \multirow{2}{*}{ Process } & \multirow{2}{*}{ Rhetorical patterns } & \multicolumn{2}{l|}{ Lower (5) } & \multicolumn{2}{l|}{ Middle (14) } & \multicolumn{2}{l|}{ Upper (6) } \\
\cline { 4 - 9 } & & & F & $\%$ & F & $\%$ & F & $\%$ \\
\hline 1 & Drafting & 1. Introductory paragraph & 1 & 20 & 7 & 50 & 6 & 100 \\
\hline & & 2. Body paragraph & 3 & 60 & 12 & 86 & 4 & 67 \\
\hline & & 3. Concluding paragraph & 1 & 20 & 13 & 93 & 5 & 83 \\
\hline 2 & Revising & 1. Introductory paragraph & 2 & 40 & 12 & 86 & 6 & 100 \\
\hline & & 2. Body paragraph & 4 & 80 & 10 & 71 & 5 & 83 \\
\hline & & 3. Concluding paragraph & 3 & 60 & 12 & 86 & 5 & 83 \\
\hline
\end{tabular}


As table 5 shows attainment of lower, middle and upper groups in developing rhetorical patterns increased in the frequency of subjects. Lower group showed low empowerment in drafting but improved in revising. Similarly, middle and upper groups also improved their accomplishment in developing essay in the revising process.

Characteristics of rhetorical patterns in drafting and revising process of lower, middle and upper groups are as follows:

1. Lower group

a. Drafting process: low introductory paragrah (20\%), fair body paragraphs $(60 \%)$ and low concluding paragraph $(20 \%)$.

b. Revising process: low introductory paragraph (40\%), very good body paragraph (80\%), and fair concluding paragraph $(60 \%)$.

2. Middle group

a. Drafting process: low introductory paragrah (50\%), very good body paragraphs (86\%) and very good concluding paragraph $(93 \%)$.

b. Revising process: very good introductory paragraph (86\%), good body paragraph (71\%), and very good concluding paragraph $(86 \%)$.

3. Upper group

a. Drafting process: excellent introductory paragrah (100\%), fair body paragraphs (67\%) and verygood concluding paragraph $(20 \%)$.

b. Revising process: excellent introductory paragraph (100\%), very good body paragraph (80\%), and very good concluding paragraph $(83 \%)$.

Rhetorical Patterns of the Essay:-

Elaboration of rhetorical patterns was done in this section. Components of intriductory paragraph, the body and concluding paragraph were rated. The findings on Table 6 showed that lower group achieved lower attainment to induce rhetorical components to make quality of the introduction better. In addition, middle and upper groups exhibitted from the lower group. Upper group even $100 \%$ of the subject succeded to develop parts of one of the rhetorical patterns.

Table 6:- Description on Rhetorical Patterns

\begin{tabular}{|c|c|c|c|c|c|c|c|}
\hline \multirow[t]{2}{*}{ No } & \multirow[t]{2}{*}{ Rhetorical elements } & \multicolumn{2}{|c|}{ Lower (5) } & \multicolumn{2}{|c|}{ Middle (14) } & \multicolumn{2}{|c|}{ Upper (6) } \\
\hline & & $\mathrm{F}$ & $\%$ & $\mathrm{~F}$ & $\%$ & $\mathrm{~F}$ & $\%$ \\
\hline \multirow[t]{5}{*}{1} & Introductory paragraph & & & & & & \\
\hline & 1. Introductory sentence & 3 & 60 & 10 & 71 & 6 & 100 \\
\hline & 2. Thesis statement & 2 & 40 & 8 & 57 & 5 & 83 \\
\hline & 3. Topic sentence & 1 & 20 & 8 & 57 & 5 & 83 \\
\hline & 4. Controlling ideas & - & - & 8 & 57 & 5 & 83 \\
\hline \multirow[t]{6}{*}{2} & Body paragraph & & & & & & \\
\hline & $\begin{array}{l}\text { 1. Transition words within and between } \\
\text { paragraphs }\end{array}$ & 3 & 60 & 10 & 71 & 6 & 100 \\
\hline & 2. Has a topic sentence & 1 & 20 & 9 & 64 & 6 & 100 \\
\hline & 3. Using appropriate details or synthesis & 1 & 20 & 7 & 50 & 4 & 67 \\
\hline & 4. Only one main idea in each paragraph & - & - & 4 & 57 & 5 & 83 \\
\hline & $\begin{array}{l}\text { 5. Supporting sentences directly relate to main } \\
\text { idea }\end{array}$ & - & - & 3 & 21 & 5 & 83 \\
\hline \multirow[t]{3}{*}{3} & Concluding paragraph & & & & & & \\
\hline & 1. Restate the controlling idea & 1 & 20 & 9 & 64 & 6 & 100 \\
\hline & 2. Have a final closing statement & - & - & 7 & 50 & 5 & 83 \\
\hline
\end{tabular}

Caracteristics of rhetorical patterns in the the essay made by the the lower, middle, and upper groups are as follows:

1. Lower group

a. Introductory paragraph: introductory sentence is fair (60\%) but thesis statement and controlling idea are low (20\%)

b. The body paragraphs: transition words is fair (60\%), topic sentence and details are low (20\%). Other components did not appear. 
c. Concluding paragraph: restatement is low (20\%) and closing statement is absence.

d. Middle group

e. Introductory paragraph: introductory sentence is fair $(60 \%)$ but thesis statement and controlling idea are low $(20 \%)$

f. The body paragraphs: transition words is fair (60\%), topic sentence and details are low (20\%). Other components did not appear.

g. Concluding paragraph: restatement is low (20\%) and closing statement is absence.

h. Upper group

i. Introductory paragraph: introductory sentence is excellent (100\%), thesis statement, topic sentence, and controlling ideas are good $(83 \%$ each).

j. The body paragraphs: transition words and topic sentence are excellent (100\% each), detail is fair (67\%), one main idea in one paragraph and supporting sentences relate to main idea are good (83\% each).

k. Concluding paragraph: restatement is excellent (100\%) and closing statement is good (83\%).

\section{Writing Strategies:-}

Results on writing strategies were obtained from structured interview. The focus of interview was to explore students' problems in writing an essay and in developing parts of the essay, e.g. introductory paragraph, the body and concluding paragraph. Strategies to overcome the problems were reported on the basis of level of attainment of the groups: lower, middle, and upper. The results of analysis were presented into drafting process that included: generating ideas, outlining, and writing the first draft; and revising that consisted of editing and proofreading.

Interviews with research subjects showed that students' problems in essay writing included: convention, rhetorical patterns, word-for-word translation, lack of content knowledge, grammatical errors, cohesion errors, lack of proofreading, and lack of academic style. Word-for-word translation is the most common problem to any students. A large number of the students literally translated Bahasa Indonesia into English when writing the essays.

The following are writing problems and solutions the students undergo that is ranked based on the results of interview.

\section{Problems to write:-}

1. Arranging ideas and structuring in plan to write

2. Outlining

3. Writing the first draft

4. Limited vocabulary

5. Lack of model

6. Grammar and sentence construction

7. Thesis statement in the introductory paragraph

8. Confused between thesis statement and topic sentence in a paragraph

9. Developing details in the body paragraphs

10. Citation or quotation

11. Making conclusion in a sentence and in a paragraph

12. Revising, editing and proofreading

\section{Strategies to overcome:-}

1. Translating

2. Consulting with bilingual dictionary

3. Referring to essay model

4. Browsing from internet and adopting the model

5. No outline, no revision, no editing, no proofreading

6. Stating outline, revising, editing and proofreading individually and with peer

7. Revisiting to achieve final copy for publishing or submission

8. Consulting with references online or in prints

9. Revising drafts several times to improve organization, parts of essay and substance

10. Controlling appropriateness among introductory paragraph, body paragraph, concluding 
paragraph; thesis statement, topic sentence in the body paragraph, developing details, transition words and conclusion.

During drafting process, some students worked with outline and generated ideas through discussion or reading sources. Some worked in mind and some wrote on paper. There were different strategies used by lower, middle and higher students to develop the essay and its specific parts: the introductory paragraph, body paragraphs, and concluding paragraph.

\section{Lower Group:-}

Planning in this study means the first process students used to generating ideas, outlining and drafting. The results show that lower students caught ideas by recalling any experiences and did not write an outline on paper. Writing an outline was very difficult and time consuming for the lower students.

Excerpt (1) testifies how lower group planned writing and wrote an outline in the drafting an essay.

I did not write an outline before writing the essay. I tracked ideas from mind and wrote whatever I remember and knew on paper. I don't think about appropriate topic but the most important is I write down the ideas on paper. (L1-DRAF)

Students of lower group also reported that planning was annoyance and took too formal and long time. Some focused too much on the outline and stared at the blank format of the outline. To write the first draft of the essay based on the outline was other difficult matters for lower students. First, stating thesis statement in the outline was complicated. Second, rhetorical patterns of an essay that consists of introductory paragraph, body paragraphs and concluding paragraph became obstacles to express ideas on the paper as seen on quote (2).

I write an outline but I cannot use as guideline of ideas an my paper. I just dropped my thought on paper, read at glance and submitted to the lecturer. I did not reread the text nor revised the contents. If I found any grammar or sentence errors, I corrected on the items that were wrong, not on the sentence or on the context. $(L-2-R E V)$.

More problems for lower group pertain to revising, editing, and proofreading. For them, revising is hard to do and they are not fully aware that revising gives benefits to improve the quality of an essay. Errors on grammars, sentences, organization, and structure of the essay are ignored by the low group.

\section{Middle Group:-}

Middle group exhibited from lower group in terms of drafting and revising strategies. First, drafting process was considered important for the students and they planned through outline. Thesis statement of the essay was developed and links to support the thesis in each body paragraph were incorporated. Second, in revising process, students made editing and proofreading with peers or by themselves. Though focuses of revision were limited, middle group students proceeded the steps of revision as the writing process suggested. Excerpt (3) testifies how middle group student maintains his thought on planning.

I am fully aware that drafting is very initial writing. Many errors in grammar, sentences, and ideas are found. Sometimes, it is very difficult to write correct sentences in drafting and I have to stop so long time to find the best words or sentence. It is bored. But, I have to do with the outline and follow ideas that I have planned. (M-3-DRF).

In addition to revising process, middle group students claimed that they improved quality of their essay from revising process. Editing is helpful to identify errors and correct the substance of the essay. They edited grammars, dictions, sentence variation, and mechanics as the first priority. The next, they revised rhetorical patterns and their contents. See quote (4) as for the example.

Revising is very important for me. I can correct many errors on sentences, for example, tenses, passive voice, plural. I can also revise the patterns, that are introduction, developing paragraphs, and conclusion. If we don't check the contents of introduction, body paragraphs, and conclusion, the results may be bad. Thesis statement does not match to the body and conclusion. (M-1-REV). 


\section{Upper Group:-}

Accomplishment on essay of higher group is better than middle and lower group. Indication was shown from the quality and strategies used by the higher group in the drafting and revising process in writing the essay.

In the drafting process, most students in higher group were aware of the presence of outlining. They asserted that prior to writing the outline, they browsed and generated ideas to focus the topic. They formulated thesis statement as a claim of the essay and tried to find evidences to support the claim. Relying on the outline, they formally drafted the essay as the outline suggested. See excerpt (5).

To me, selecting certain topic is very important. I usually browse through internets or discuss with friends about the topic I am going to write. Initially, I jot down the ideas on a paper as an outline then I revise if I think new ideas are better. I will write confidently if I consider that my outline is complete. (H-1-DRAF).

Actions with care on revising process were stated by the higher group students. Surprisingly, higher group students did all aspects in the revising process: evaluating the paper, editing, revising and proofreading. In the evaluation process, students focused to see rhetorical patterns. Identification on thesis statement, topic sentence, developing details in introductory paragraph, body paragraphs, and concluding paragraph was done. The next, students checked any errors in the whole texts. The last step, students asked their peers and teachers to proofread the paper.

Overall, results of interview revealed that majority of students literally translated from L1 to English when writing English essays. The students seemed to be bothered by lack of vocabulary knowledge. Literal translation was done for two main causes: use of bilingual dictionaries and lack of exposure to English materials. Lack of exposure resulted word-to-word translation and writing deficiencies including grammar errors, cohesion errors, and lack of academic style.

\section{Discussion:-}

Writing quality is affected by strategy use. Processes for writing differ from one writer to another and from one situation to the next (Reid, 1992). However, three basic stages of writing process are common: pre-writing, drafting, and post-writing through which writers practice a number of strategies. Pre-writing includes generating ideas relevant to the subject (Dupont, 2004). Drafting involves writing the first version and composing thoughts in sentences and paragraphs (Winterowd \& Murray, 1988). Post-writing stage cleaned up errors such as spelling, omission, extra spaces, formatting, and punctuation errors (Dupont, 2004).

Writing is a multidimensional communicative process, concerning "the generation, analysis, and synthesis of ideas; the organization of discourse; the control of sentence structure; the vocabulary, spelling, and mechanics" (Williams, 2007:12). Writing is related to emotion, cognition, motivation, logical reasoning, linguistic skills and contextual adaptation; it is also based on sufficient acquisition of English, so some people say writing can best reflect an individual's education.

EFL writing practice has two goals: language acquisition and writing skill practice. The first goal focused on linguistic accuracy, discourse pattern, and made students write from sentence to paragraph to essay. This way, students were equipped to write with a clear and rigid format: an introduction with thesis statement, supporting paragraphs, a concluding paragraph, sometimes some rhetorical devices like compare-and-contrast or cause-andeffect were used. The latter goal focused on writing process, express meaning and content (Budiharso, 2006; Yiu, 2012; Solikhah, 2017).

Majority of students produced low quality essays because they were not serious or critical enough when producing drafts or revising. The prominent problems related to writing attitude and habits. When composing, some students did not use certain strategies like to think critically about writing process, plan and develop contents, edit or even revise writing outputs (Ismail, et.al., 2010). They simply wrote without much concern to their writing steps or process, e.g. outline and brief draft.

Regarding translation process in writing, students used more bilingual dictionary than monolingual because bilingual dictionaries may lead to errors. In writing process, students consulted on both the dictionaries. To overcome this problem, students are advised to use both bilingual and monolingual dictionaries. 
The final finding drawn in the present study was that most students finished writing process without proofreading. The students were not aware the function of proofreading to qualify an essay. Proofreading means examining the essay carefully for errors in grammar, spelling, punctuation and style. Proofreading can make writing more professional and clearer.

\section{Conclusion:-}

This study provides insights that writing characteristics EFL learners to write an essay are about identical. In the process writing, drafting, revising and strategies to write an essay in this study showed similarities with other studies. Lower students were absence of some aspects in the drafting and revising process. Lower group did not write outline and produced first draft without planning. Thesis statement, topic sentence and concluding paragraph did not appear. The middle gruop was able to produce thesis stetament, body paragraphs and conclusion, but they focused less on revising and proofreading. The higher group exhibitted by performing all aspects of an essay in each rhetorical patterns. Drafting and revising were used appropriately. Overall, all groups asserted literal translation to develop ideas and overcome problems on diction.

\section{References:-}

1. Arnaudent, M. and Barret M.M. (1981). Paragraph Development: A Guide for Students of English as a Second Language. Rowly, Massachusetts: Prentice Hall, Inc.

2. Budiharso, Teguh. (2006). The Rhetoric Features of English and Indonesian Essays Made by EFL Undergraduate Students. TEFLIN, 17(2):54-86.

3. Caudery, Tim. (1995). What the "Process Approach" Means to Practising Teachers of Second Language Writing Skills. Teaching English as a Second or Foreign Language, 1(4): 1-14.

4. Dupont, L. (2004). Writing key stones: Essays and research. New York: Pearson Education.

5. Hammad, E. Abdullah. (2014). Essay writing problems and multiple language acquisition, JSMULA, 2(1): 1-12.

6. Http://www.time4writing.com. (2017). Editing and Revising. Retrieved on January 26, 2017.

7. Http://www.eiu.edu/-writing/tips. Strategies to Editing and Revising. Retrieved on Janury 15, 2017.

8. Http://gustavu-edu/writingcenter/handout.editing. (2017). General Strategies for Editing and Proof Reading. Retrieved on February 3, 2017.

9. Http://pwr.la.psu.edu/resources/graduate-writing-center/hand (2017). Strategies for Revising Academic Writing. Retrieved on March, 2017.

10. Ismail, Noriah; Hussin, Supyan \& Darus, Saadiyah. (2012). ESL Students' Attitude, Learning Problems, and Needs for Online Writing, GEMA Online Journal of Language Studies, 12(4): 1089-1108.

11. Kirszner, Lauire G \& R. Mendell. (1980). Patterns for College Writing: A Theoretical Reader Guide. New York: St. Matin's Press, Inc.

12. Krashen, Stephen D. (1984). Writing: Research, Theory and Application. Oxford: Pergamon Institute of English.

13. Langan. (1984). College Writing Skills. New York: McGraw-Hill Book Company.

14. Monica. (1996). Editing and Revising. Berkeley, California: Student Learning Center, University of California, Berkeley.

15. Pouladian, Nima; Sadegh Bagheri, Mohammad \& Sadighi, Firooz. (2017). An Analysis of Errors in Writing Skill of Adult Iranian EFL Learners Preparing for the IELTS. International Journal of English Linguistics, 7(3): 85-96.

16. Reid, Joy M. (1982). The Process of Composition. New Jersey: Prentice Hall Inc.

17. Smalley R. and Ruetten. (1983). Refining Composition Skills: Rhetoric and Grammar for ESL Students. New York: Macmillan Publishing Company.

18. Solikhah, Imroatus. (2017). Linguistic Problems on the Essay Writing by EFL Students, Indonesian Journal of Language Teaching and Linguistics, 2(1): 1-13. Http://ijoltl.pusatbahasa.or.id.

19. University of North Caroline. (2014). Editing and Revising. Chapel Hill, North Caroline: The Writing Center of University of North Carolina.

20. Vanderpyl, Gregory, D. (2012). The Process approach as Writing Instruction in EFL Classroom. MA TESOL Collection 545.

21. Williams, Jessica. (2007). Teaching writing in second and foreign language classrooms. London: World Publishing Corporation.

22. White, R. and Arndt, V. (1991). Process Writing. London: Longman.

23. Wingersky, J, Boerner, Holguin-Balogh. (1992). Writing Paragraphs and Essays: Integrating Reading, Writing, and Grammar Skills. Belmont, California: Wadsworth Publishing Company.

24. Yiu, Aij. 2012. Analysis of the Problems of the Chinese College Students' EFL Classroom Writings, International Education Studies, 5(5): 199-203. 